\title{
EKSISTENSI SINDEN KARNATI KELOMPOK JAIPONG REMBEL DI DESA SALEM KECAMATAN SALEM KABUPATEN BREBES
}

\author{
Ela Susanti \\ I. Joko Wiyoso, S. Kar, M. Hum \\ Alumni mahasiswa Jurusan Sendratasik, Fakultas Bahasa dan Seni, Universitas \\ Negeri Semarang \\ lendianbj@gmail.com
}

\begin{abstract}
Kesenian jaipong Rembel tumbuh dan berkembang di Kabupaten Brebes. Kesenian jaipong Rembel masih menjadi tontonan favorit masyarakat Kabuapaten Brebes, sehingga banyak kelompok kesenian sinden jaipong yang muncul di Kabupaten Brebes. Kelompok jaipong Rembel di Kabupaten Brebes banyak di undang untuk acara hajatan, khitanan, dan pernikahan. Di antara kelompok jaipong Rembel yang paling diminati dan paling dikenal oleh masyarakat Kabupaten Brebes yaitu Kesenian jaipong Rembel yang ada di Desa Salem Kecamatan Salem Kabupaten Brebes.
\end{abstract}

Kata Kunci: Eksistensi, Sinden Jaipong Rembel.

\section{A. PENDAHULUAN}

Eksistensi berasal dari kata eksis yang berarti ada. Kaitanya dengan seni, eksistensi dapat diartikan untuk menciptakan beberapa bentuk simbol yang menyenangkan, namun bukan hanya mengungkapkan segi keindahan saja, tetapi dibalik itu terkandung maksud baik bersifat pribadi, sosial maupun fungsi yang lain. Menurut Hadi (dalam Nina, 2015: 11).

Keberadaan manusia sebagai kesadaran bisa dikenal dengan eksistensi. Artinya, sebuah keadaan yang berkat kesadarannya, manusia mampu melampai batas situasi-situasi yang melingkarinya mampu mengatasi apa yang fakum dan datum lingkupnya dalam proses yang disebut "transendensi" melampaui pagar-pagar yang membatasi, alam yang mengungkumnya (Mudji 2005: 355).

Kesenian tradisional adalah kesenian yang khas yang erat sekali hubunganya bahkan sama sekali tidak terlepas dari latar belakang alam dan segala aspek kehidupan masyarakat daerah sebagai pendukungnya. Selain dari pada itu karena umur dan kekuatanya maka kesenian tradisional menjadi cermin watak dan sifat masyarakat (Suwaji, $1988: 54$ ).

Tradisional merupakan istilah yang berasal dari bahasa latin "traditio" artinya mewariskan. Untuk memberi tekanan batasan awal dari yang disebut tari tradisional adalah, tari-tarian yang sudah cukup lama berkembang sampai saat ini sebagai warisan budaya yang turun temurun dari leluhurnya (Rosjid 1997: 5). 
Kesenian tradisional juga mempunyai fungsi untuk tujuan magic. Tujuan magic maksudnya adalah untuk mempengaruhi manusia dan lingkunganya seperti mendatangkan hujan, memperoleh kesejahteraan dan memperoleh ketentraman hidup. Fungsi penyajian kesenian tradisional secara magic adalah sebagai berikut: 1) memanggil kekuatan gaib, 2) pengusir ruh jahat, 3) peringatan kepada nenek moyang, 4) memanggil ruh yang baik, 5) upacara adat untuk pergantian waktu, 6) upacara untuk peringatan seseorang, 7) sebagai keindahan. Menurut Sach (dalam Marsi,2009: 10).

Pesindhen/Sindhen adalah istilah yang menuju kepada personal atau pelaku; orang yang menjadi peraganya adalah wanita; sehingga istilah sindhen ada yang memberi batasan pengertian solo vokal puteri yang menyertai karawitan (Muriah 2013: 22).

Sindhen, berasal dari kata "sendhu" dan "ing". Sendhu atau nyendhu mempunyai pengertian memotong atau nyelani. Dalam suatu percakapan, sering orang lain memotong percakapan itu dan inilah yang dinamakan nyendhu atau nyelani. Sindhenan adalah materi vokal yang membuat aspek garap instrumen, yang didalamnya terkandung unsur-unsur yang hars diolah dan diterjemahkan melalui bahasa musikal (Darsono 2008: 199-120).

Nama jaipong konon merupakan kata cengah (senggakan pada karawitan jawa), yang merupakan respon dari bunyi kendang yang banyak terdengar pada keliningan gamelan karawangan. Ada tiga kata yang bisa diteriakan oleh para nusisi dalam memberikan aksen pada pemain kendang itu, yaitu jaipong, jakinem, dan jainem.

Daya tarik tari jaipongan terletak pada goyangan pinggul si penari, serta pemain kendang yang sangat dinamis yang berasal dari teknik permainan kendang pencak silat. Maka dari itu, walaupun busana para wanita biasa-biasa saja, artinya kain panjangnya menutupi seluruh bagian bawah, baju berlengan panjang tanpa menghadirkan desain yang memperlihatkan bagian yang akan merangsang, hiasan kepala yang bergelungpun cukup sederhana tetapi memiliki daya pukau yang tinggi (Soedarsono, 2002 : 209-212).

\section{B. METODE PENELITIAN}

Pendekatan penelitian pada kesenian sinden jaipong karnati merupakan penelitian dengan menggunakan metode kualitatif dengan sifat deskriptif. Nyoman ( 2010 : 306) menjelaskan bahwa penelitian kualitatif adalah metode dengan intensitas, nilai-nilai, dibedakan dengan kualitatif, metode sebagai pengukuran dalam angka, jumlah, sedangkan interprestasi dalam penafsiran.keseluruhan data yang baru diperoleh dari lapangan melalui metode pengumpulan data jelas belum berarti apa-apa, bahkan dianggap benda mati. Penelitian yang dilakukan peneliti menggunakan metode kualitatif dengan bersifat deskriftif. Pendekatan dalam penelitian ini menitik beratkan eksistensi sinden Karnati dalam kelompok jaipong Rembel di Desa Salem Kecamatan Salem Kabupaten Brebes.

Lokasi penelitian adalah tempat dimana penelitian dilaksanakan atau tempat dimana seseorang 
melaksanakan penelitian. Tujuan ditetapkannya lokasi penelitian adalah agar diketahui dengan jelas objek yang akan diteliti. Lokasi penelitian ini di Desa Salem Kecamatan Salem Kabupaten Brebes. Karena Karnati itu adanya di Desa Salem Kecamatan Salem Kabupaten Brebes.

Sasaran dalam penelitian ini adalah eksistensi sinden Karnati kelompok jaipong Rembel di Desa Salem Kecamatan Salem Kabupaten Brebes dan faktor-faktor apa saja yang mendukung eksistensi sinden Karnati dalam kelompok jaipong Rembel Desa Salem Kecamatan Salem Kabupaten Brebes.

Teknik pengumpulan data yang digunakan dalam penelitian ini adalah teknik observasi, wawancara, dan dokumentasi. Teknik keabsahan data yang digunakan adalah triangulasi yang diartikan sebagai teknik pengumpulan data bersifat menggabungkan dari berbagai teknik pengumpulan data sumber yang telah ada. Teknik analisis data yang digunakan dalam penelitian ini adalah reduksi data dan penarikan kesimpulan.

\section{HASIL PENELITIAN DAN PEMBAHASAN.}

Gambaran Umum Lokasi Penelitian

Kecamatan Salem merupakan salah satu bagian dari wilayah Kabupaten Brebes, Propinsi Jawa Tengah, terletak dibagian selatan paling barat dari wilayah Kabupaten Brebes batas-batas wilayah Kecamatan Salem meliputi Kecamatan Banjar Harjo di sebelah Utara, Kecamatan Bantarkawung di sebelah Timur, Kabupaten Cilacap di sebelah Selatan, serta Kabupaten Kuningan ( Propinsi Jawa Barat ) di sebelah Barat.
Kecamatan Salem merupakan daerah pegunungan (400-900 mdpl), dimana salem sendiri berada dilembah yang dikelilingi hutan dan deretan pegunungan di sekitarnya, berhawa sejuk (16-22 $\left.{ }^{\circ} \mathrm{C}\right)$ dan memiliki panorama yang indah. Lanskape Kecamatan Salem mirip mangkok bakso. Di kiri kanan adalah daerah pegunungan-pebukitan yang cukup tinggi sementara di tengah-tengahnya adalah wilayah Kecamatan salem. Dengan kondisi daerah tersebut wilayahnya merupakan daerah yang sangat terisolir.

Berdasarkan lokasi daerah yang dimiliki tersebut, maka secara militer wilayah Salem merupakan daerah pertahanan yang efektif. Dengan menyandang daerah pertanian yang subur, maka tidak aneh wilayah Kecamatan Salem merupakan daerah strategis secara politis.

\section{Profil Sinden Karnati Kelompok Jaipong Rembel}

Rembel adalah kelompok kesenian jaipong dangdut yang ada di Desa Salem Kecamatan Salem Kabupaten Brebes. Kelompok ini melestarikan seni tradisional, yang khas ragam gerak dan musiknya yang berakar pada perpaduan jaipong dan dangdut, Karnati merupakan sinden yang ada di dalam group Rembel.

Kelompok Rembel merupakan sebuah kelompok kesenian yang berpijak pada tradisi. Tradisi yang menjadi pijakan adanya kesenian sinden Karnati . Oleh karena itu sinden Karnati bergabung ikut ke dalam kelompok sinden jaipong Rembel sebagai dari kekuatan agar kesenian sinden jaipong Rembel bisa tetap eksis sampai sekarang. Sinden Karnati mulai bergabung pada kelompok 
Rembel pada tahun 2009, perkembangan sinden Karnati di kelompok jaipong Rembel sudah 6 tahun.

Asal mulanya sinden karnati di group rembel ini merupakan langkah awal dari eksistensi. Pembahasan asal mulanya karnati berasal dari sejarah dan perkembangan di group rembel pada tahun 2009-2015, Di group Karnati berkaitan dengan dinamika perkembanganya, dinamika perkembangan pada saat Karnati mulai bergabung di group rembel pada tahun 2009. Dinamika ini membahas tentang pasang surut naiknya popularitas serta jumlah pementasan dari masa ke masa. Selain karena pijakan tradisinya, unsur menghibur pada kelompok jaipong Rembel dikuatkan dengan adanya lawakan sinden yang memperkuat kelompok jaipong Rembel.

Pijakan tradisi pada kelompok jaipong Rembel terlihat dari gerak yang sederhana yang sedikit melawak para penonton dan musik pengirirngnya. Musik pengirirngnya pada kelompok jaipong Rembel merupakan musik campuran antara karawitan jawa dan musik modern. Kelompok sinden Karnati dalam kelompok jaipong Rembel berusaha mempertahankan tradisinya dan mempertahankan eksistensinya di Desa Salem Kecamatan Salem.

\section{Eksistensi Sinden Karnati}

Awal mulanya Karnati menjadi sinden sejak umur 15 tahun sampai dengan umur 52 tahun. Karnati menjadi sinden karena turunan dari ibunya sejak jaman dulu, sebelum orang tuanya Karnati meninggal orang tua Karnati telah mengajari Karnati menyinden pada umur 10 tahun.
Karnati adalah anak pertama dari tiga bersaudara. Dari ketiga saudara tersebut Karnatilah yang bisa menurunkan bakat orang tuanya itu, Karnati mempunyai satu anak perempuan yang sekarang sudah dewasa. Walaupun anak Karnati itu adalah perempuan akan tetapi dia tidak bisa menyinden sama seperti Karnati.

Karnati hanya tinggal berdua bersama anaknya, karnati hanyalah seorang janda sederhana yang berprofesi sebagai sinden. Selain pekerjaanya sebagai sinden, Karnati memiliki pekerjaan lainya seperti bertani dan sedikit membuka warung kecil-kecilan untuk memenuhi kebutuhan sehari-hari.

Pertama kali Karnati menjadi sinden ia bergabung kedalam "Group Jipang" pada tahun 1980. Pada waktu itu Karnati berusia 17 tahun, seiring berjalanya waktu dengan Karnati masuk Group Jipang, Group Jipang di senangi masyarakat pada tahun 19802005. Karnati bergabung ke dalam Group Jipang dari tahun 1980-2005. Perlahan-lahan Karnati keluar dari Group Jipang karena semakin lama Group Jipang menunjukan pertunjukan yang hanya begitu-begitu saja, sehingga masyarakat merasa jenuh akan pertunjukan Group Jipang.

Karnati mulai bingung karena jadwal manggung yang semakin menurun dan kurang minatnya masyarakat saat itu. Karnati mulai mencari job-job manggung diluar Group Jipang, inisiatif Pak Carik untuk menjadi daya tarik masyarakat akhinya Karnati mencoba ikut dengan Group Rembel pada saat itu. Dengan berjalanya waktu Karnati mulai merasa nyaman bergabung ke dalam Group Rembel pada tahun 2006, karena Group Rembel memadukan 
jaipongan dan dangdut sehingga masyarakat lebih tertarik dengan Group Rembel. Dengan adanya Karnati dalam Group Rembel, Group Rembel jadi semakin eksis di masyarakat sampai sekarang.

\section{Bentuk Pertunjukan Jaipong Rembel}

Berdasarkan hasil wawancara dengan Pak Carik selaku pemimpin kelompok jaipong Rembel tanggal 2 April 2015 bahwa kelompok jaipong Rembel diadakan pada siang hari mulai pukul 09.30 WIB sampai pukul 16.00 WIB dan diadakan pada malam hari mulai pukul 21.00 WIB sampai dengan pukul 01.30 WIB. Sajian pertunjukan dimalam dan siang hari sama dan tidak ada bedanya. Urutan penyajian pertunjukan kelompok sinden jaipong karnati sebagai berikut

1) Pra acara : pertunjukan dimulai dengan pembukaan pembawa acara yang ditujukan untuk saibul hajat.

2) Persembahan : persembahan dari kelompok jaipong Rembel yaitu sinden daan penari jaipong.

\section{Tata Rias}

tata rias wajah penari dan sinden pada kelompok jaipong Rembel dilakukan oleh para pemain jaipong Rembel. Kelompok jaipong Rembel tidak memiliki perias propesional. Alasan kelompok ini tidak mengambil perias dari luar yaitu karena masalah biaya dan menghemat pengeluaran. Alat-alat make up yang digunakan yaitu Bedak dasar, bedak tabur, pensil alis, bulu mata, eye liner, blush on, kuas blush on, lipstik, hair spray, sisir sasak, sanggul, spon dan eye shadow.

Tata rias pada kelompok jaipong Rembel hanya ada pada penari dan artis dangdut saja, sedangkan pemusik tidak menggunakan riasan sama sekali. Tata rias wajah menggunakan rias kolektif. Rias kolektif bertujua untuk mengubah penampilan fisik yang kurang sempurna. Tatarias wajah kolektif merupakan tata rias yang sering dilakukan oleh masyarakat. Maka tatarias ini selalu berhubungan dengan penampilan yang natural dan sederhana. Namun terlihat sempurna, karena kekurangan dan kelebihan di wajah terlihat lebih segar.

\section{Tata Lampu}

Kelompok jaipong Rembel biasanya dipentaskan di luar ruangan dan dapat dipetaskan pada malam hari dan siang hari. Kelompok kesenian jaipong Rembel dalam penyajianya menggunakan alat penerang lampu apabila dipentaskan di malam hari. Lampu yang dibutuhkan yaitu ada lampu netral general, putih, hijau ,merah, dan kuning. Lighting dalam pementasan kelompok jaipong Rembel biasanya sudah ada satu paket bersama group jaipong Rembel, kelompok ini sudah menyediakan sendiri.

Pementasan kelompok jaipong Rembel yang dilakukan pada siang hari, maka cahaya lampu tidak dibutuhkan oleh kelompok jaipong Rembel. Pada siang hari kelompok jaipong Rembel hanya dengan menggunakan bantuan sinar matahari, dan apabila dilakukan pada malam hari jelas kelompok jaipong Rembel membutuhkan lampu untuk penerang.

\section{Tata Suara}

Penampilan kelompok jaipong Rembel menggunakan tata suara yang sesuai dengan ukuran luasnya area pertunjukan dan luasnya area penonton. Tata suara biasanya 
menggunakan sound system yang terdiri dari sound monitor dan sound yang memancarkan suara keluar. Tata suara biasanya sudah disediakan oleh pemilik group jaipong rembel.

Sound monitor berfungsi sebagai monitor atau sebagai media agar suara yang masuk ke area panggung bersamaan dengan suara yang keluar dari area panggung, sehingga akan menambah konsentrasi para pemain dalam memainkan alat musiknya dan menari dengan tempo yang jelas sesuai dengan tempo yang sebenarnya.

\section{Bentuk Panggung atau Tempat Pertunjukan}

Pertunjukan kesenian jaipong Rembel dilakukan kapan saja dimana saja tergantung yang membutuhkan, kapan dan dimana kesenian jaipong Rembel dipentaskan. Kesenian jaipong Rembel tidak memiliki waktu yang khusus dalam pertunjukan, namun kebanyakan penanggap meminta pementasan kesenian jaipong Rembel dilakukan pada waktu siang hari yaitu pukul 09.30 WIB sampai dengan selesai dan dimalam hari pukul 21.00 WIB sampai dengan selesai. Kesenian jaipong Rembel biasanya dipentaskan di ruangan terbuka atau di halaman rumah, agar bisa terkesan dan bisa membaur dengan para penonton.

Pementasan sinden Karnati yang dilakukan oleh kelompok jaipong Rembel pimpinan Pak Carik tidak memiliki panggung yang ajeg, biasanya menyesuaikan sesuai dengan halaman rumah si pemilik hajat. Ruangan yang disediakan oleh penanggap biasanya disediakan di luar ruangan dengan pola persegi.

\section{PENUTUP}

Simpulan

Eksistensi Sinden Karnati kelompok Jaipong Rembel tercermin pada kemampuan yang selalu mempertahankan keutuhan kelompok dan menjaga kualitas vokalnya pada saat pertunjukan sehingga masyarakat yang ada di Kabupaten Brebes dan sekitarnya memiliki keinginan yang tinggi untuk mengundang Kelompok Sinden Karnati dalam kelompok Jaipong Rembel pada acara yang akan diselenggarakkan.

$\begin{array}{ll}\text { Bagi } & \text { Kelompok } \begin{array}{r}\text { Jaipong } \\ \text { Rembel walaupun }\end{array}\end{array}$
modernisasi yang ada di dunia luar tentunya tidak akan meninggalkan tradisi Kesenian Jaipong yang sesungguhnya.

Bagi para pemain Kelompok Jaipong Rembel selalu menjaga kekompakan dan kerjasama dalam acara pertunjukan berlangsung serta disipli dan tanggung jawab yang kuat dengan cara mentoleransi sesama pemain agar Kesenian Jaipong Rembel semakin dikenal dan mampu pentas diluar Kabupaten Brebes.

\section{REFERENCES}

\author{
Alimandan.1985. Sosiologi Ilmu \\ Pengetahuan Berpradigma \\ Ganda. Jakarta : CV
}

Ambarwangi, S., \& Suharto, S. (2014). REOG AS MEANS OF STUDENTS'

APPRECIATION

AND

CREATION IN ARTS AND CULTURE BASED ON THE LOCAL WISDOM.

Harmonia: Journal Of Arts Research And Education, 14(1), 37-45. 
doi:http://dx.doi.org/10.15294/

harmonia.v14i1.2789

Ambarwangi, S., \& Suharto, S. (2013).

PENDIDIKAN

MULTIKULTURAL DI

SEKOLAH MELALUI

PENDIDIKAN SENI

TRADISI. Harmonia: Journal

Of Arts Research And

Education, 13(1).

doi:http://dx.doi.org/10.15294/

harmonia.v13i1.2535

Alo. 2003. Dasar-dasar Komunikasi Antar Budaya. Yogyakarta : Pustaka Pelajar.

Bastomi, Suwaji. 1988. Apresiasi Kesenian Tradisional. IKIP Semarang Press.

Budiarti, M. (2014). KONSEP KEPESINDENAN DAN ELEMEN-ELEMEN

DASARNYA. Harmonia: Journal Of Arts Research And Education, 13(2). doi:http://dx.doi.org/10.15294/ harmonia.v13i2.2781

Darsono. 2008. Jurnal Pengetahuan, Pemikiran dan Kajian Tentang "Bunyi". ISI Surakarta: Volume 8 No 2.

Dharsono. 2007. Kritik Seni. Bandung : Rekayasa Sains .

Edi Sedyawati . 2006 . Kajian Arkeologi Seni Dan Sejarah. Jakarta : PT Raja Grafindo.

Jazuli, M. (2011). POPULARITAS SINDHEN. Harmonia: Journal Of Arts Research And
Education, 9(2). doi:http://dx.doi.org/10.15294/ harmonia.v9i2.637

Koentjaraningrat. 1995. Manusia Dan Kebudayaan di Indonesia. Jakarta : Djambatan.

Koentjaraningrat. 2005. Pengantar ilmu Antropologi. Jakarta : PT . Rineka Putra.

Kumbini, Marsi. 2009. Bentuk Penyajian Seni Krangkeng Kuda Sari Desa Ademsoyang Kecamatan Taman Kabupaten Pemalang. Skripsi Unnes.

Kurniawati, Ika. 2009. Bentuk Dan Fungsi Tari Dalam Kesenian Kenthongan. Skripsi Unnes.

Laelly, Novita. 2009. Sinden Dalam Cerbung Tembang Katresna Karya Atas S. Danusubroto. Skripsi Unnes.

Maryono. 2012. Estetika Seni Pertnjukan Tari. ISI Surakarta : Volume 10 No 2. Modernisasi. SkipsUnnes.

Maryono, -. (2011). REOG KEMASAN SEBAG AIASET PARIWISATA UNGGULAN KABUPATEN PONOROGO (The Packes Reog as the high tourism ofPonorogo residence). Harmonia: Journal Of Arts Research And Education, 8(2). doi:http://dx.doi.org/10.15294/ harmonia.v8i2.788

Muriah. 2013. Kehadiran Suryati Dalam Dunia Kepesindenan 
Gaya Banyumas. Surakarta : ISI PRESS Surakarta.

Nanang. 2004. Pengantar Estetika . Bandung : Rekayasa Sains.

Lestari, P. (2014). MAKNA SIMBOLIK SENI BEGALAN BAGI PENDIDIKAN ETIKA MASYARAKAT. Harmonia: Journal Of Arts Research And Education, 13(2). doi:http://dx.doi.org/10.15294/ harmonia.v13i2.2782

Patton, Michael Quinn . 2006 . Metode Evaluasi Kualitatif. Jogjakarta : Pustaka Pelajar Rajawali.

Putra, B. (2013). PENGEMBANGAN MODEL KONSERVASI KESENIAN LOKAL SEBAGAI KEMASAN SENI WISATA DI KABUPATEN SEMARANG. Harmonia: Journal Of Arts Research And Education, $\quad 12(2)$. doi:http://dx.doi.org/10.15294/ harmonia.v12i2.2525

Ratna, Nyoman Kutha .2010 .Metodologi Penelitian. Yogjakarta : Pustaka Pelajar.

Rohidi, Tjetjep Rohendi. 2000. Kesenian Dalam Pendekatan Kebudayaan. Bandung : STSI Press.

Rosjid. 1979. Seni Tari III. Jakarta : C.V. Angkasa.

Soedarsono. 2006. Trilogi Seni Penciptaan Eksistensi Dan Kegunaan Seni. Yogjakarta : BD ISI Yogjakarta.
Sugiyino. 2013. Metode Penelitian Pendidikan. Bandung : Alfabeta

Sumandiyo. 2005. Sosiologi Tari. Yogyakarta : Pustaka Pelajar.

Sunahrowi. 2010. Pengantar Ilmu Budaya. Yogyakarta : Pelangi Pushibing.

Utari. 2014. Eksistensi Kesenian Lasehan Dalam Pesatnya Arus Globalisasi Dan Modernisasi. Skripsi Unnes.

Widodo, Broto Sejati. 2008. Macapat. Semarang : Universitas Negeri Semarang Press.

Wulansari, Nina. 2015. Eksistensi Kelompok Tayub Manunggal Laras Desa Sriwedari Kecamatan Karanganyar Kabupaten Ngawi. Skripsi Unnes.

Wiyoso, J. (2013). MOTIVASI MASUKNYA CAMPURSARI KE DALAM PERTUNJUKAN JARAN KEPANG. Harmonia: Journal Of Arts Research And Education, 12(1). doi:http://dx.doi.org/10.15294/ harmonia.v12i1.2217

Widodo, W., Ganap, V., \& Soetarno, S. (2017). Laras concept and its triggers: A case study on garap of jineman Uler Kambang. Harmonia: Journal Of Arts Research And Education, 17(1), 75-86. doi:http://dx.doi.org/10.15294/ harmonia.v17i1.10771 